\title{
Vena cava renal izquierda en un paciente con carcinoma de células renales
}

\author{
C. Pascual Mateo*, M. Luján Galán*, N. Rodríguez García*, J.M. Gómez de Vicente*, \\ D. Santos Arrontes*, E. Aguilar**, A. Berenguer Sánchez*
}

*Servicio de Urología. **Servicio de Radiología. Hospital de Getafe. Madrid.

Actas Urol Esp 2005; 29 (7): 693-695

\section{RESUMEN}

VENA CAVA RENAL IZQUIERDA EN UN PACIENTE CON CARCINOMA DE CÉLULAS RENALES

Presentamos un caso de vena cava renal izquierda diagnosticado mediante CT abdominal durante el estudio de extensión de un paciente por carcinoma de células renales. Esta anomalía es muy rara pero su conocimiento antes de la cirugia es importante para evitar complicaciones durante el procedimiento quirúrgico.

Palabras claves: Vena cava inferior izquierda. Nefrectomía.

\section{ABSTRACT \\ LEFT INFERIOR VENA CAVA WITH RENAL CELL CARCINOMA.}

We presented a case of inferior vena cava on the left side diagnosed by abdominal CT scan during the study of a renal cell carcinoma in the right side. This anomaly is very rare but it may suppose a more difficult approach to the nephrectomy.

Keywords: Vena cava. Inferior. Left-sided. Nephrectomy.

$\mathrm{L}$ as anomalías de la vena cava inferior son malformaciones poco frecuentes pero cuyo conocimiento es relevante a la hora de llevar a cabo una cirugía aórtica o en el retroperitoneo. Hoy en día son fácilmente diagnosticadas por la gran difusión de las pruebas de imagen. Presentamos un caso en el que se diagnosticó una vena cava inferior izquierda en el estudio de un carcinoma de células renales.

\section{CASO CLÍnICo}

Paciente varón de 69 años con antecedentes de hipertensión arterial, herniorrafia inguinal y cirugía de próstata, que fue remitido a consulta de Urología por hematuria y dolor en fosa renal derecha. En la ecografía abdominal se identificó una masa renal derecha en polo superior de $8,5 \mathrm{~cm}$ de diámetro. Ante este hallazgo se solicita
CT abdominal que fue informado como masa renal sólida derecha heterogénea en polo superior de unos $9 \mathrm{~cm}$ de diámetro con probable infiltración de suprarrenal ipsilateral y adenopatías paraaórticas derechas y preaórticas menores de $1 \mathrm{~cm}$; vena cava inferior en disposición izquierda.

Ante los hallazgos mencionados, se llevó a cabo un estudio de extensión con radiografia de tórax normal y gammagrafía ósea con dudosa lesión metastásica a nivel de D12 que se descartó mediante radiografía selectiva. Analíticamente todos los parámetros se encontraban dentro de la normalidad. Una vez descartada extensión extrarrenal se procedió a nefrectomía radical derecha en la cual se identificaron diversas anomalías vasculares: vena cava izquierda que cruzaba anteriormente a la aorta a nivel de los vasos renales, así como una vena espermática drenando en ve- 
na renal derecha y venas polares anómalas. La masa renal parecía infiltrar cápsula de Gerota y suprarrenal ipsilateral. (Fig. 1) El diagnóstico anatomopatológico fue de carcinoma de células renales de células claras de 9 centímetros de diámetro mayor de grado IV de Fuhrman (pT3bGIV), con afectación de cápsula renal y de vena renal pero sin identificar afectación de suprarrenal.

\section{DISCUSIÓN}

La vena cava inferior (VCI) se forma durante la sexta a décima semana de gestación. Alteraciones en este proceso de embriogénesis pueden generar varias anomalías anatómicas: duplicación de la VCI, transposición o VCI en el lado izquierdo, vena renal izquierda retroaórtica y vena renal izquierda circumaórtica. Las anomalías de la VCI son raras, siendo las más frecuentes las dos últimas ${ }^{1}$.

Las dos primeras alteraciones (duplicación y transposición) son diagnosticadas mediante pruebas de imagen al identificar una estructura tubular en el lado izquierdo con o sin una vena cava normosituada (respectivamente) ${ }^{2}$. Esta disposición puede plantear confusión con una linfadenopatía retroperitoneal ${ }^{3}$. Igualmente es importante identificar y valorar la situación de la vena renal izquierda con respecto a la aorta (vena renal normal, retroaórtica o circumaórtica). Chaung et al. llevaron a cabo una clasificación de estas anomalías en cuatro tipos: tipo A o uréter retrocavo, tipo B o VCI normal, tipo $\mathrm{C}$ o $\mathrm{VCI}$ izquierda y tipo $\mathrm{BC}$ o duplicación $\mathrm{VCI}^{4}$.
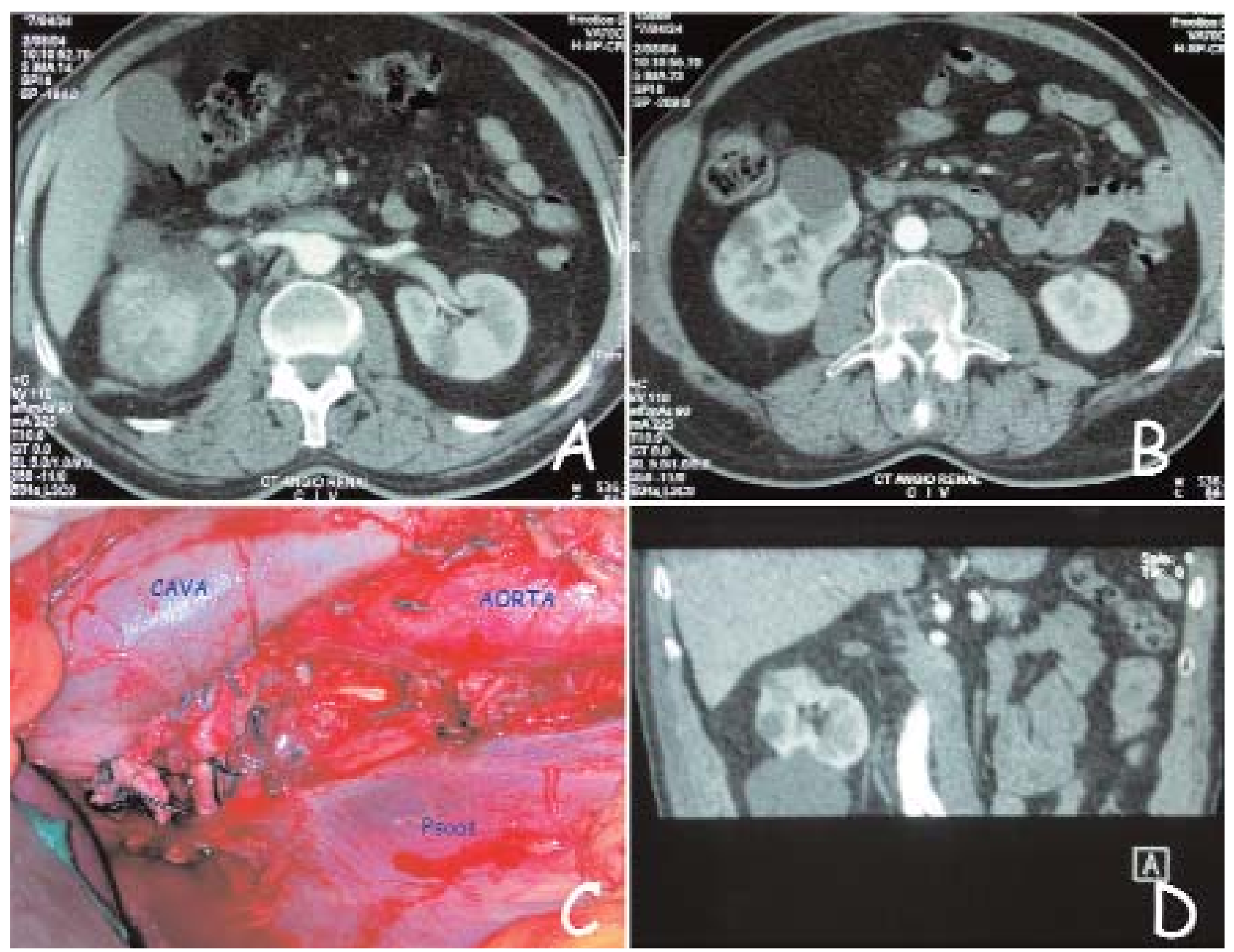

FIGURA 1. A) Corte abdominal donde se observa la masa renal derecha y una vena cava en suposición anterior a la aorta. B) Corte inferior CT abdominal donde se observa la vena cava en situación izquierda. C) Fotografía tras la nefrectomía de la disposición de los vasos. D) Reconstrucción coronal del cruce aorto-cava. 
La VCI izquierda tiene un frecuencia estimada del 0,2\%-0,5\%3,5. La VCI izquierda generalmente cruza al lado derecho anteriormente a la aorta a nivel de las arterias renales, como es en este caso (Fig. 1), aunque en ocasiones cruza posteriormente o forma parte de un vena renal izquierda circumaórtica $^{1}$. Estas anormalidades pueden complicar la realización de una nefrectomía sobre todo si tenemos en cuenta la posibilidad de otras anomalías vasculares asociadas. Existen algunos precedentes de tumor renal con VCI izquierda como el comunicado por Chaung et al. Estos autores, como nosotros, también identifican otras anomalías vasculares asociadas como venas polares aberrantes.

\section{REFERENCIAS}

1. Giordano JM, Trout HH. Anomalies of the inferior vena cava. J Vasc Surgery 1986;3:924-928.

2. Mayo J, Gray R, St Louis E, et al: Anomalies of the inferior vena cava. AJR 1983;140:339-345.

3. Bass JE, Redwine MD, Kramer LA, et al: Spectrum of congenital anomalies of the inferior vena cava: cross-sectional imaging findings. Radiographics 2000;20:639-652.

4. Chaung VP, Mena E, Hoskins PA. Congenital anomalies of the inferior cava: Review of embryogenesis and presentations of a simplified classification. Br J Radiol 1974;47:206-213.

5. Namiki M, Itoh $\mathrm{H}$, Yoshioka, et al: Inferior vena cava on left side with left renal cell carcinoma. Urology 1982;20:330-331.

Dr. C. Pascual Mateo.

Servicio de Urología. Hospital de Getafe.

Ctra Toledo, Km 12,500 - 28905 Madrid

E-mail: carlospascualmateo@yahoo.es

(Trabajo recibido el 9 diciembre 2004) 